\title{
Texture Characteristics and Anisotropic Superplasticity of AZ61 Magnesium Alloy
}

\author{
Y. N. Wang ${ }^{1,2}$ and J. C. Huang ${ }^{1, *}$ \\ ${ }^{1}$ Institute of Materials Science and Engineering; Center for Nanoscience and Nanotechnology, National Sun Yat-Sen University, \\ Kaohsiung, Taiwan 804, R. O. China \\ ${ }^{2}$ Department of Materials Engineering, Dalian University of Technology, Dalian 116024, P. R. China
}

The texture evolution and mechanical anisotropy in an extruded AZ61 Mg alloy are examined. After warm extrusion, the alloy exhibits a refined grain structure and a strong basal texture. The tensile behaviors are examined in extruded specimens with the loading axis oriented at $0^{\circ}$, $45^{\circ}$ and $90^{\circ}$ to the extrusion direction. The $45^{\circ}$ specimens exhibit lower yield stresses and higher ductility. The possible reasons for the mechanical anisotropy based on the Schmid factor calculations are analyzed.

(Received June 11, 2003; Accepted September 16, 2003)

Keywords: texture, microstructure, $X$-ray diffraction, anisotropic superplasticity, magnesium alloy

\section{Introduction}

Magnesium alloys are emerging as potential candidates for numerous applications, especially in transportation vehicles or lightweight enclosures for 3C (computer, communication and consumer electronic) products owing to their good properties, such as low density and high specific strength. ${ }^{1)}$ However, Mg alloys have been limited by the low ductility at room temperature due to the hexagonal crystalline structure. The processing mean in improving their poor workability is mainly to refine the grain size through extrusion or rolling. Hot or warm extrusion seems to be more favorable, since rolling tends to produce edge cracking when the temperature is not properly controlled. During extrusion, a significant crystallographic texture may be induced, and the texture would impose an important influence on the mechanical properties, ${ }^{2-5)}$ as well as on the formability during the subsequent press forming or hot forging.

The deformation model in hexagonal crystals is mainly based on the following three distinct slip systems and one twinning system: (i) basal $\{0001\}\langle 11 \overline{2} 0\rangle$; (ii) prismatic $\{10 \overline{1} 0\}\langle 11 \overline{2} 0\rangle$; (iii) pyramidal $\{11 \overline{2} 2\}\langle 11 \overline{2} \overline{3}\rangle$ and $\{10 \overline{1} 1\}\langle 11 \overline{2} 0\rangle$, and (iv) twinning $\langle 10 \overline{1} 1\rangle$ slip on $\{10 \overline{1} 2\}$. The formation of deformation texture in hexagonal metals and its alloys during rolling will develop in accordance with the relative contributions from the above four deformation paths. Through these deformation processes, the slip plane will gradually rotate toward the rolling plane and the slip direction toward the rolling direction.

Previous studies on the texture development in rolled hexagonal materials have demonstrated the presence of strong (0002) fiber textures. ${ }^{6)}$ The textures of cold-rolled hexagonal metals and alloys can be categorized into three groups according to their $c / a$ ratios, namely materials with $c / a$ ratios greater than, approximately equal to, and less than the ideal value of 1.633. The simulated (0002) and (10 $\overline{1} 0)$ pole figures by our self-written software for the cold-rolled sheet textures ${ }^{7)}$ with different $c / a$ categories are schematically illustrated in Fig. 1, which are in agreement with experimental results. ${ }^{6,8)}$ Metals and alloys with $c / a$ ratios

*Corresponding author, E-mail address: jacobc@mail.nsysu.edu.tw

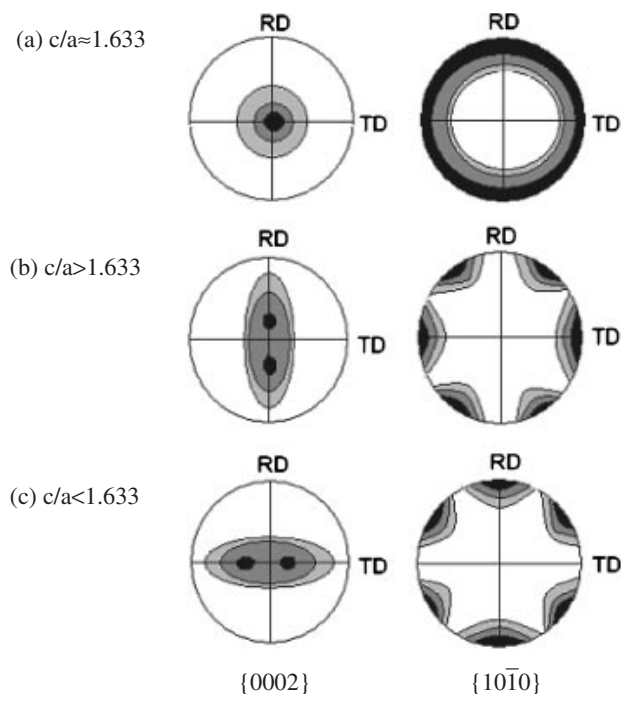

Fig. 1 Simulated rolling texture in terms of $\{0002\}$ and $\{10 \overline{1} 0\}$ pole figures in HCP metals with $c / a$ ratio (a) approximately equal to 1.633 (such as $\mathrm{Mg}$ ), (b) greater than 1.633 (such as $\mathrm{Zn}$ ), and (c) less than 1.633 (such as $\mathrm{Ti}$ ).

approximately equal to the ideal $c / a$ ratio of 1.633 , such as $\mathrm{Mg}$, tend to form basal fiber textures (as in Fig. 1(a)) during rolling. Metals and alloys with $c / a$ ratios above the ideal, such as $\mathrm{Zn}$ (1.856) and $\mathrm{Cd}(1.885)$, tend to exhibit textures with basal poles tilted $\pm 15 \sim 25^{\circ}$ away from the normal direction toward the rolling direction, the $\langle 11 \overline{2} 0\rangle$ poles aligned with the rolling direction, and the $\langle 10 \overline{1} 0\rangle$ directions pointed parallel to the transverse direction (Fig. 1(b)). Finally, the metals and alloys, possessing $c / a$ ratio less than 1.633 such as $\mathrm{Zr}$ (1.589) and $\mathrm{Ti}$ (1.587), tend to form textures with basal poles tilted $\pm 20 \sim 40^{\circ}$ away from the normal direction toward the transverse direction, the $\langle 10 \overline{1} 0\rangle$ poles aligned with the rolling direction, and the $\langle 11 \overline{2} 0\rangle$ directions pointed parallel to the transverse direction (Fig. 1c). Such texture characteristics in hexagonal crystals are mainly related to the relative contributions from the three distinct slip systems and one twinning system mentioned above. In general, the $c / a$ ratio reflects the activation of the different slip systems.

The recrystallization texture in hexagonal materials was 
rarely studied. The (0002) basal texture in recrystallized hexagonal metals is usually evolved with a $\sim 30^{\circ}$ rotation about $\langle 0001\rangle$ pole or a $\sim 90^{\circ}$ rotation about $\langle 10 \overline{1} 0\rangle .^{9-11)}$ However, other types of texture change upon recrystallization have also been noted. ${ }^{12,13)}$

Recently, a number of studies on the deformation modes in $\mathrm{Mg}$ alloy specimens processed by equal channel angular press were reported. ${ }^{2)}$ The specimens were subject to " $c$-axis compression", "c-axis extension", or "c-axis constraint", and the consequent tensile response was discussed. ${ }^{2)}$ It was found that there existed direct correspondence between the deformation texture and tensile flow stress. Continuous efforts on the texture influence are worth making for future forming and shaping applications of the commercial $\mathrm{Mg}$ alloys.

In contrast to the rolling texture evolution in hexagonal materials studied, the texture developments in extruded $\mathrm{Mg}$ plates or bars have not been widely reported. The present work is to demonstrate the texture characteristics of a warm extruded and annealed AZ61 Mg alloy, as well as the influence of texture on the tensile properties and superplastic deformation behaviors, emphasizing the anisotropic properties.

\section{Experimental Procedures}

The AZ61 (Mg-5.88 mass\%Al-0.74 mass\%Zn) alloy, purchased from the CDN Company, Deltabc, Canada, was fabricated through semi-continuous casting. Warm extrusion at $300^{\circ} \mathrm{C}$ with an extrusion ratio of $\sim 50: 1$ was applied, resulting in a sheet measuring $2 \mathrm{~mm}$ in thickness and $10 \mathrm{~mm}$ in width. Annealing treatments were performed at 250, 350 and $450^{\circ} \mathrm{C}$ for various periods of time in order to study the evolution of microstructure and texture of this alloy.

The textures of the extruded and annealed specimens were measured by X-ray diffraction using the Schulz method in a Siemens D5000 diffractormeter with a $\mathrm{K}_{\alpha}$-Co radiation. The orientation distribution function (ODF) was calculated from the experimental pole figures $\{0002\},\{10 \overline{1} 2\},\{10 \overline{1} 3\}$ and $\{11 \overline{2} 0\}$ data by using the series expansion method including positivity techniques. ${ }^{14)}$

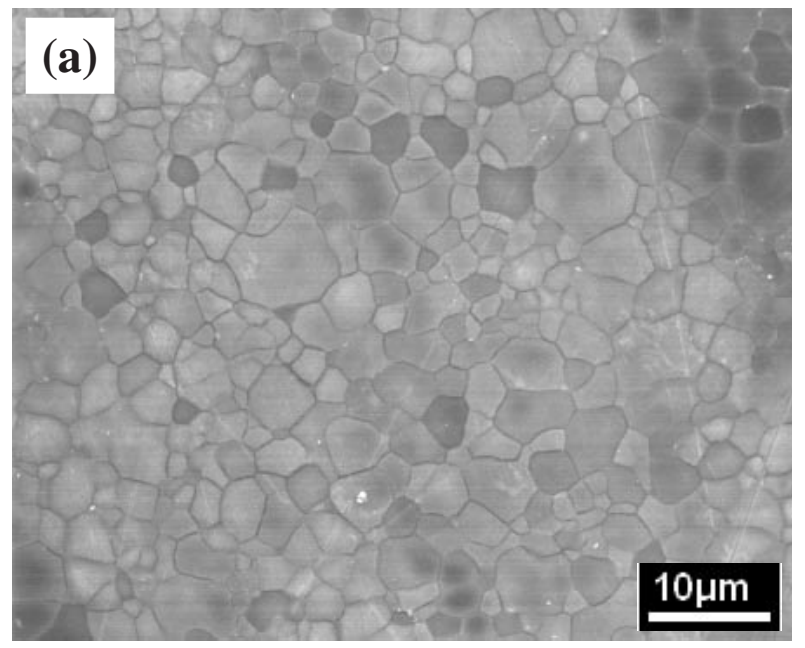

All the tensile test specimens, with a gauge length of $10 \mathrm{~mm}$ and width of $3 \mathrm{~mm}$, were prepared by line cutting. Three directions (with $0^{\circ}, 45^{\circ}$, and $90^{\circ}$ with respect to the extrusion direction) were chosen as the tensile axis for the test specimens in order to study the anisotropy of tensile properties at room temperature, as well as the superplastic behaviors at $300 \sim 400^{\circ} \mathrm{C}$ and an initial stain rate of $1 \times 10^{-3} \mathrm{~s}^{-1}$. The tensile test was performed using the Instron 5508 machine equipped with a three zone furnace, with temperature control within $\pm 1^{\circ} \mathrm{C}$. The microstructure of the specimens was examined using optical microscopy and scanning electron microscopy (SEM). The specimens were etched using a reagent consisting of $10 \mathrm{ml}(8.5 \mathrm{vol} \%)$ acetic acid $+10 \mathrm{ml}(8.5 \mathrm{vol} \%)$ water $+100 \mathrm{ml}(83 \mathrm{vol} \%)$ ethanol, plus $5 \times 10^{-3} \mathrm{~kg}$ picric acid solid powders.

\section{Results}

\subsection{Grain structure}

After extrusion, the coarse equiaxed colonies of the $\alpha-\mathrm{Mg}$ phase measuring $\sim 125 \mu \mathrm{m}$ in the as-cast AZ61 Mg alloy were changed into refined grains measuring $\sim 6.5 \mu \mathrm{m}$, implying that strong dynamic recrystallization has fully taken place during warm extrusion. The grain structure observed from the longitudinal flat section of the extruded specimen is shown in Fig. 2(a). Microstructure examinations indicated that annealing at all investigated temperatures $(250$, 350 and $450^{\circ} \mathrm{C}$ ) resulted in normal grain growth. A typical SEM micrograph of the specimen annealed at $450^{\circ} \mathrm{C}$ for $30 \mathrm{~min}$ is shown in Fig. 2(b). The average grain size becomes $\sim 12 \mu \mathrm{m}$. Table 1 lists the grain size measurements for the current AZ61 alloys.

Table 1 Grain size measurements (in unit of $\mu \mathrm{m}$ ) of the extruded AZ61 alloy upon annealing at different temperatures for different periods of time.

\begin{tabular}{cccc}
\hline Annealing temperature $\left({ }^{\circ} \mathrm{C}\right)$ & $0.5 \mathrm{~h}$ & $1.5 \mathrm{~h}$ & $3 \mathrm{~h}$ \\
\hline 250 & 6.5 & 7 & 7 \\
350 & 8 & 8 & 10 \\
450 & 12 & 13 & 15 \\
\hline
\end{tabular}

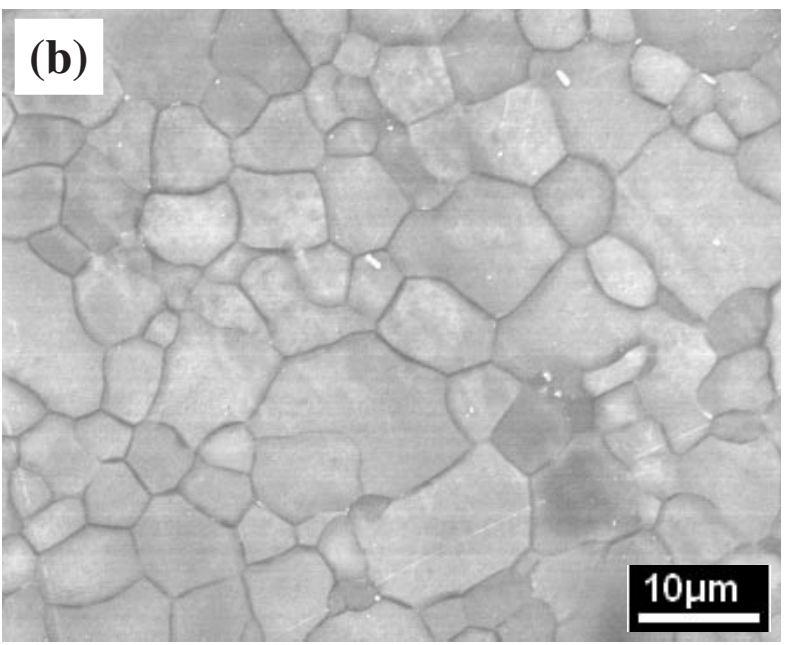

Fig. 2 SEM micrographs of the AZ61 specimens in the (a) as-extruded condition and (b) annealed at $450^{\circ} \mathrm{C}$ for $0.5 \mathrm{~h}$. 


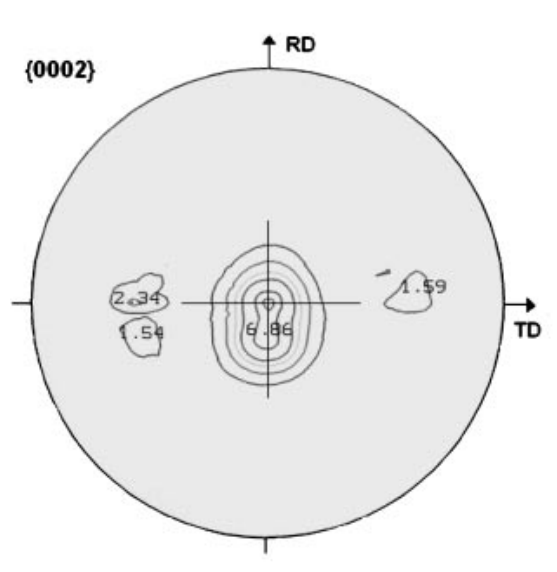

(a)

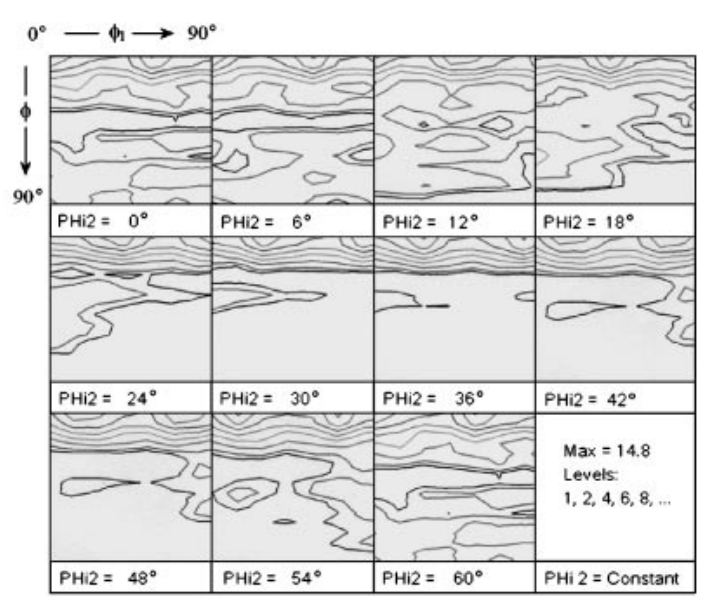

(b)

Fig. 3 Texture of the extruded AZ61 specimens: (a) $\{0002\}$ pole figure, and (b) constant $\phi_{2}$ sections of ODF.

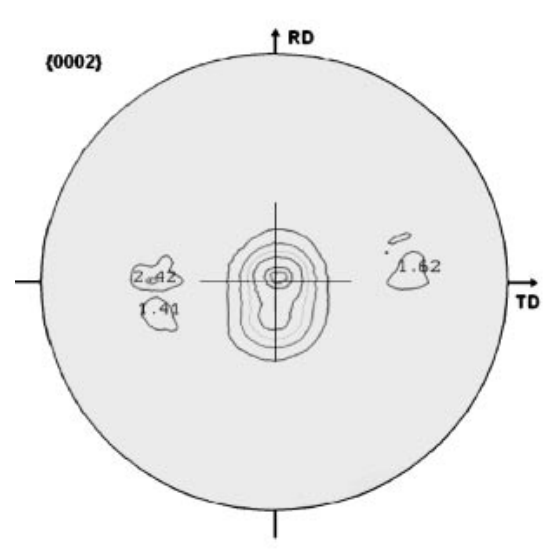

(a)

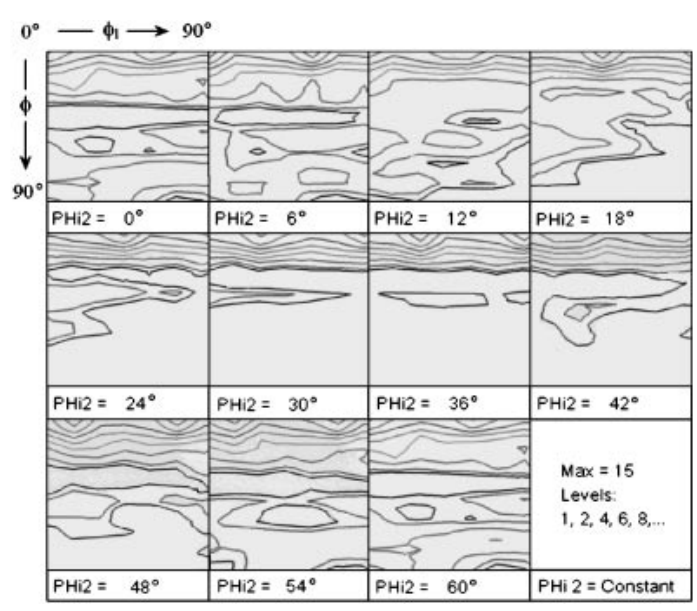

(b)

Fig. 4 Texture of the AZ61 specimens annealed at $450^{\circ} \mathrm{C}$ for $30 \mathrm{~min}$ : (a) $\{0002\}$ pole figure, and (b) constant $\phi_{2}$ sections of ODF.

\subsection{Texture measurements}

The pole figure and the constant $\phi_{2}$ sections of ODF plot for the extruded specimen are shown in Fig. 3. It can be seen from Fig. 3(b) that the $\phi_{2}=0 \sim 60^{\circ}$ sections with $\phi=0^{\circ}$, $\phi_{1}=0 \sim 90^{\circ}$ of the ODF show a complete $\{0002\}$ basal texture which scatters around $\pm 30^{\circ}$ away from the exact $\{0002\}$ basal texture. Among the $\{0002\}$ basal texture, the strongest peak is centered at a position with $\phi_{2}=0^{\circ}, \phi=0^{\circ}$, $\phi_{1}=0^{\circ}$ and $60^{\circ}$, namely $\{0002\}\langle 10 \overline{1} 0\rangle$ texture component. In addition, other weak $\{11 \overline{2} 2\}$ plane texture and $\{10 \overline{1} 2\}$ plane texture can also be seen at $\phi_{2}=0^{\circ}, \phi=45^{\circ}$, $\phi_{1}=0 \sim 90^{\circ}$ and $\phi_{2}=30^{\circ}, \phi=40^{\circ}, \phi_{1}=0 \sim 90^{\circ}$ locations, respectively. The incomplete weak $\{11 \overline{2} 0\}$ plane texture which located at $\phi_{2}=0^{\circ}, \phi=90^{\circ}, \phi_{1}=0^{\circ} \sim 90^{\circ}$ was also found. The strong (0002) basal fiber texture observed in the as-extruded AZ61 sheet resembles very much the typical texture observed in rolled pure $\mathrm{Mg}$ or $\mathrm{Mg}$ alloys. ${ }^{6,7)}$ Although with different stress states and die constraint during extrusion and rolling, the resulting texture in $\mathrm{Mg}$ alloys appears to be similar.

The pole figure and ODF plots of the AZ61 alloy annealed at $450^{\circ} \mathrm{C}$ for $30 \mathrm{~min}$ are shown in Fig. 4, which are typical plots for all of the annealed specimens. It can be seen that the annealed texture is essentially similar to the original warm extrusion texture. This suggests that the equixed fine grains in the as-extruded AZ61 alloy are a result of dynamic recrystallization that occurred during the warm extrusion. Further annealing at $250-450^{\circ} \mathrm{C}$ could not promote secondary recrystallization. This experimental result also indicates that the changes in textures are not pronounced during normal grain growth of this alloy, namely, no preferential or abnormal grain growth occurred.

\subsection{Tensile property}

The results of room temperature tensile tests are presented in Table 2, showing the anisotropic tensile properties of the extruded AZ61 alloy specimens. It can be seen that the $45^{\circ}$ specimen exhibits slightly lower yield stress (YS) and higher

Table 2 Room tensile properties of the textured AZ61 alloy loaded at a strain rate of $1 \times 10^{-3} \mathrm{~s}^{-1}$.

\begin{tabular}{cccc}
\hline Angle to extrusion direction & YS $(\mathrm{MPa})$ & UTS $(\mathrm{MPa})$ & $\delta(\%)$ \\
\hline $0^{\circ}$ & 232 & 315 & 26.8 \\
$45^{\circ}$ & 212 & 314 & 31.0 \\
$90^{\circ}$ & 251 & 315 & 24.5 \\
\hline
\end{tabular}




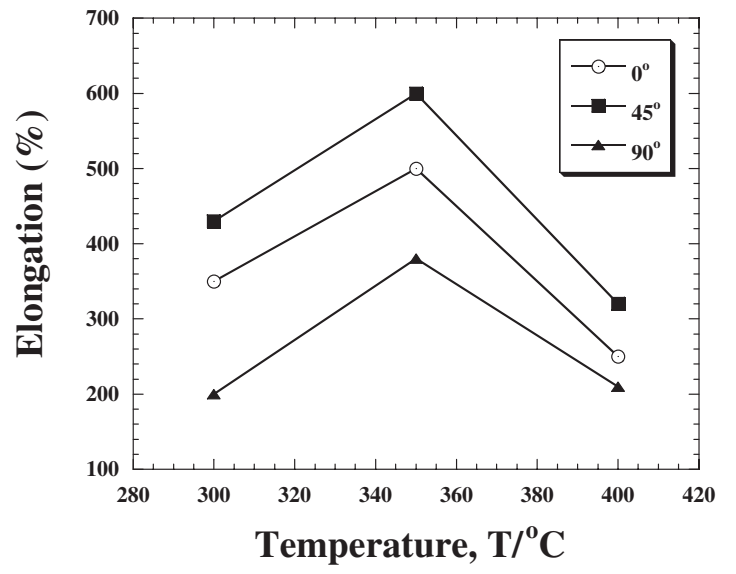

Fig. 5 The variation of elongation-to-failure as a function of loading temperature (at a strain rate of $1 \times 10^{-3} \mathrm{~s}^{-1}$ ).

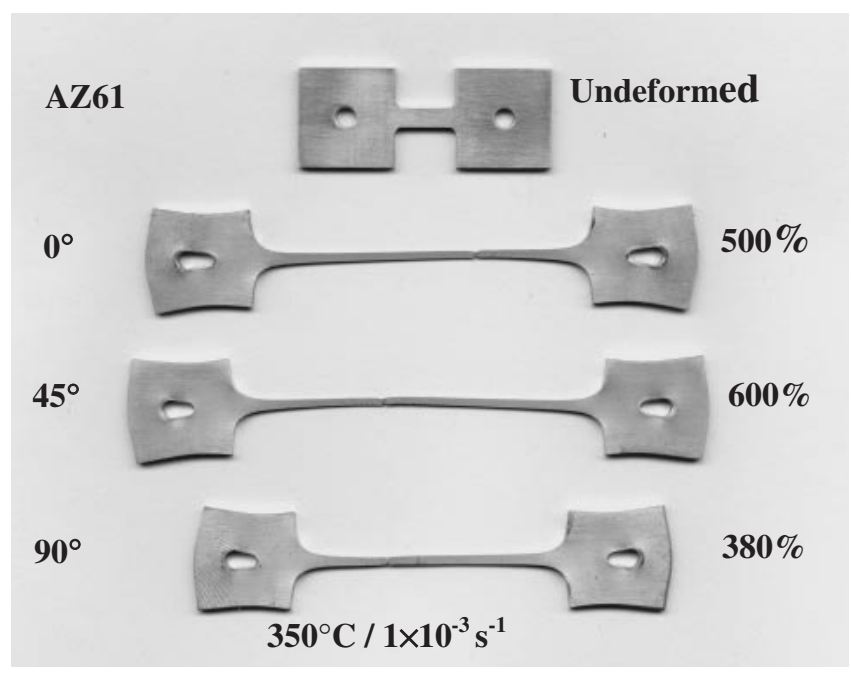

Fig. 6 Typical fractured specimens with different loading angles to the extrusion direction loaded at $350^{\circ} \mathrm{C}$ and strain rate of $1 \times 10^{-3} \mathrm{~s}^{-1}$.

elongation $(\delta)$, as compared with the $0^{\circ}$ and $90^{\circ}$ specimens. The influence of grain shape and grain size on the tensile properties is neglected owing to the equiaxed gains in the warm extruded specimen as shown in Fig. 2(a). Therefore, it seems that the mechanical anisotropic behaviors are mainly attributed to the macroscopic orientation.

The superplastic elongations of the three different specimens at 300,350 and $400^{\circ} \mathrm{C}$ under a strain rate of $1 \times 10^{-3} \mathrm{~s}^{-1}$ are plotted in Fig. 5. The fractured samples loaded at $350^{\circ} \mathrm{C}$ are given in Fig. 6. It can be seen that the relatively higher elongation is consistently achieved in the specimen oriented at $45^{\circ}$ to the extrusion direction, and the relatively lower elongations are achieved in the specimens oriented at $0^{\circ}$, and especially, at $90^{\circ}$ to the extrusion direction. It appears that the resulting texture also influences the superplastic deformation, as discussed in Sec. 4.2.

\section{Discussion}

\subsection{Texture evolution}

The extrusion process at elevated temperatures can be simply regarded as the combination of deformation and sequential recrystallization process. Although the texture evolution in warm extruded sheets have rarely been published, a number of investigations have described the cold rolling texture variations in hexagonal metals according to their $c / a$ ratios. $^{6-8)}$ For the $\mathrm{Mg}$ alloys with $c / a$ ratios approximately equal to the ideal $c / a$ ratio of 1.633 , the basal $\{0002\}$ fiber texture tends to form during rolling. The origin of such a texture may be understood in terms of the slip systems operating on basal planes. As easy slip in $\mathrm{Mg}$ and $\mathrm{Mg}$ alloys occurs on basal plane along the $\langle a\rangle$ direction, the rolling process would align the $\{0002\}$ basal plane to lie parallel to the sheet plane and the easy slip direction $\langle 11 \overline{2} 0\rangle$ to align parallel to the rolling direction, resulting in the $\{0002\}\langle 11 \overline{2} 0\rangle$ texture. With increasing temperature, nonbasal slip system, such as $\{11 \overline{2} 2\}\langle c+a\rangle$ and $\{10 \overline{1} 2\}\langle a\rangle$ will be active to some extents, ${ }^{15)}$ promoting the formation of nonbasal textures such as the weak $\langle 11 \overline{2} 2\rangle \|$ ND fiber texture and the $\{10 \overline{1} 2\} \|$ ND fiber texture.

However, the deformation texture components mentioned above will be changed owing to the sequential dynamic recrystallization. Based on the oriented growth theory of recrystallization texture, ${ }^{6)}$ the main deformation texture $\{0002\}\langle 11 \overline{2} 0\rangle$ will preferentially transfer into the $\{0002\}\langle 10 \overline{1} 0\rangle$ texture during sequential recrystallization, which happens to be the main texture component in the current warm extruded AZ61 alloy. This is because the grain boundaries with misorientations up to $\pm 30^{\circ}$ rotation around $\langle 0001\rangle$ may have higher mobility than that of other misorientations for hexagonal metals. ${ }^{6)}$ Throughout the current study, the texture observed in the extruded and extruded and then annealed AZ61 sheets appears to be similar to those previously reported in rolled $\mathrm{Mg}$ and $\mathrm{Mg}$ base alloys. Note that such similarities are only applied to extruded sheets, not to extruded bars or tubes, as found in our parallel studies on the AZ31, AZ61 and AZ91 alloys. ${ }^{16)}$

Perez-Prodo and Ruano ${ }^{17)}$ have also studied the texture evolution in AZ31 alloys extruded at $300^{\circ} \mathrm{C}$ into a thicker plate of $5 \mathrm{~mm}$ in thickness, and they found the presence of $\{0002\}$ basal fiber texture, with weak $\{10 \overline{1} 0\}$ and $\{11 \overline{2} 0\}$ fibers. Upon recrystallization at $450{ }^{\circ} \mathrm{C}$, the $\{0002\}$ basal and $\{10 \overline{1} 0\}$ fibers are retained while the $\{11 \overline{2} 0\}$ fiber was strengthened. If the extruded AZ61 is recrystallized at an even higher temperature of $520^{\circ} \mathrm{C}$, the $\{11 \overline{2} 0\}\langle 1 \overline{100}\rangle$ texture is formed. The current study on the as-extruded thin sheet of $2 \mathrm{~mm}$ in thickness found mainly the $\{0002\}$ fibers, with very minor $\{11 \overline{2} 2\}$ and $\{10 \overline{1} 2\}$ plane textures, plus an incomplete $\{11 \overline{2} 0\}$ plane texture. The minor difference between the current results with those of Perez-Prodo and Ruano ${ }^{17)}$ might be due to the thicker plate which results in the greater throughout-thickness texture gradient. The texture of the current AZ31 extruded sheets after further annealing at 250$450^{\circ} \mathrm{C}$ for $0.5-3 \mathrm{~h}$ still maintained the existing texture. Since there was no apparent abnormal grain growth, the unusual $\{11 \overline{2} 0\}\langle 1 \overline{1} 00\rangle$ recrystallization texture, as found by PerezProdo and Ruano, ${ }^{17)}$ was not observed in the current case. It seems that, within the practical press forming working temperature range of $250-450^{\circ} \mathrm{C}$, the texture formed during the warm extrusion would not alter much. 


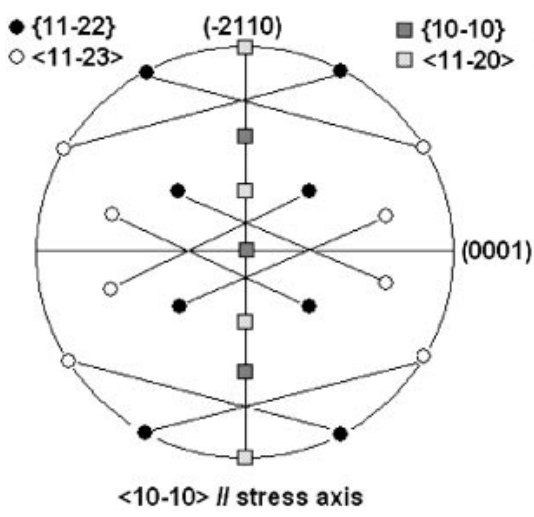

(a)

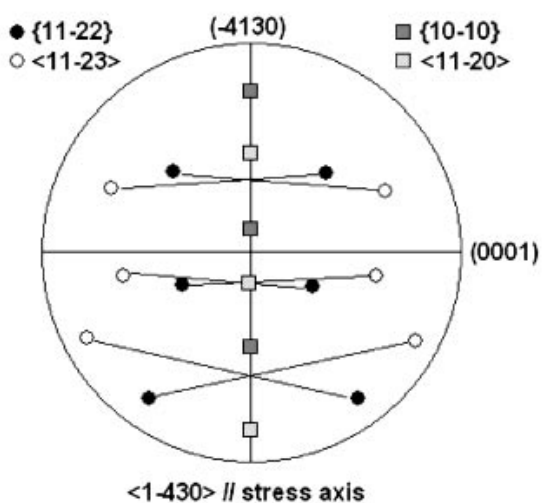

(b)

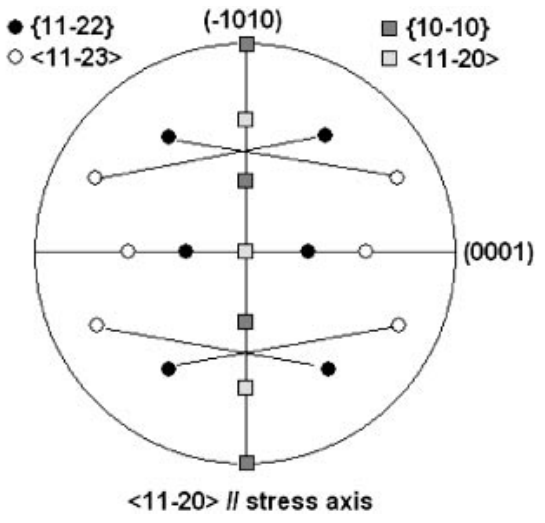

(c)

Fig. 7 Distribution of some slip planes and slip directions of samples oriented at (a) $0^{\circ}$ (b) $45^{\circ}$ and (c) $90^{\circ}$ to the tensile axis. The lines in the drawings connect the slip plane and direction in one slip system. Note that exact angle between $\langle 1 \overline{4} 30\rangle$ with the tensile axis is 46.1 degree rather than 45 degree. The plot in (b) is an illustration roughly showing the relative orientation relationship.

Table 3 Schmid factor analysis on the textured AZ61 alloy.

\begin{tabular}{ccccc}
\hline Samples & Basal slip* & Prismatic slip & Pyramidal slip & Pyramidal slip \\
& $\{0002\}\langle a\rangle$ & $\{10 \overline{1} 0\}\langle a\rangle$ & $\{10 \overline{1} 2\}\langle a\rangle$ & $\{11 \overline{2} 2\}\langle c+a\rangle$ \\
\hline $0^{\circ}$ & Average 0.10 & Average 0.29 & Average 0.20 & Average 0.24 \\
& $1 / 3(0+0.15+0.15)$ & $1 / 3(0.43+0.43+0)$ & $1 / 3(0+0.30+0.30)$ & $1 / 3(0.36+0.36+0)$ \\
$45^{\circ}$ & Average 0.11 & Average 0.33 & Average 0.23 & Average 0.23 \\
& $1 / 3(0.17+0.12+0.05)$ & $1 / 3(0.23+0.27+0.50)$ & $1 / 3(0.34+0.18+0.18)$ & $1 / 3(0.03+0.41+0.26)$ \\
$90^{\circ}$ & Average 0.11 & Average 0.29 & Average 0.20 & Average 0.22 \\
& $1 / 3(0.17+0.08+0.08)$ & $1 / 3(0.43+0.43+0)$ & $1 / 3(0+0.30+0.30)$ & $1 / 3(0.45+0.11+0.11)$ \\
\hline
\end{tabular}

* Basal plane is inclined about 10 degree to tensile axis based on to the experimental ODF.

\subsection{Tensile anisotropy}

It is well known that the yield stress, $\sigma_{\mathrm{y}}$, of polycrystalline metals depends on the critical resolved shear stress, $\tau_{\mathrm{c}}$, and orientation factor (Schmid factor), $S$, which is corresponding to the strongest texture component (similar to a single crystal): ${ }^{18)}$

$$
\tau_{\mathrm{c}}=S \sigma_{\mathrm{y}}, \quad \text { and } \quad S=\cos \theta \cos \phi,
$$

where $\theta$ and $\phi$ are the angles between the slip plane normal and direction with respect to the tensile axis, respectively.

Previous investigations ${ }^{19)}$ have shown that, in largegrained $\mathrm{Mg}$ alloys, twinning is observed from the early stage of room temperature plastic deformation and serves as an additional deformation mechanism to basal slip in order to satisfy the von-Mises criterion. However, fine-grained $\mathrm{Mg}$ alloys exhibit no noticeable twinning in the early stage of plastic deformation. ${ }^{20)}$ Therefore, it is expected that in the present fine-grained $(6.5 \mu \mathrm{m})$ AZ61 alloy, twinning deformation mechanism could be neglected. Although there exists basal texture in the present AZ61 Mg alloy, the basal dislocation slip is still dominant owing to the large-scale spreading of basal texture (Fig. 3). It follows that additional dislocation mechanisms are needed in place of twinning. Note that the non-basal $\langle a\rangle$ dislocations are not sufficient to ensure homogeneous deformation; activation of $\langle c+a\rangle$ slip is still necessary to satisfy the von-Mises criterion. In the present work, the non-basal slip systems, namely, the prismatic $\langle a\rangle$ slip system, pyramidal $\langle a\rangle$ slip system and pyramidal $\langle c+a\rangle$ slip system are all considered in addition to the basal slip system.

The distributions of prismatic $\langle a\rangle$ slip system and pyramidal $\langle c+a\rangle$ slip system in samples oriented at $0^{\circ}$, $45^{\circ}$ and $90^{\circ}$ to the tensile stress axis are illustrated in Fig. 7. Table 3 shows the results of calculated Schmid factors for different slip systems. It can be realized from Table 3 that, in the $45^{\circ}$ sample, not only the primary basal slip system $\left(S_{\max }=0.17\right)$ but also the prismatic $\langle a\rangle$ slip system $\left(S_{\max }=\right.$ $0.50)$ and the pyramidal $\langle a\rangle$ slip system $\left(S_{\max }=0.41\right)$ have the highest (or nearly the highest) Schmid factors. Because the yielding of materials is dominated by a slip system having the highest Schmid factor, it is expected that the yield strength in the $45^{\circ}$ sample at room temperature (Table 2 ) is the lowest among other $0^{\circ}$ and $90^{\circ}$ samples.

Meanwhile, the average values or the uniformity of Schmid factors in all slip systems acting along $45^{\circ}$ are also in general higher than those acting along $0^{\circ}$ and $90^{\circ}$, resulting in the higher degree of freedom for deformation and hence the higher ductility at room temperature (Table 2). Furthermore, although the average values of Schmid factors of all the slip systems in both $0^{\circ}$ and $90^{\circ}$ samples are nearly the same, the uniformity of Schmid factors of the slip systems in the $0^{\circ}$ sample, especially for the primary basal slip system, are better than that in the $90^{\circ}$ sample. This will result in the lower yield strength and higher ductility of the $0^{\circ}$ sample as compared with the $90^{\circ}$ sample (Table 2). The latter result suggests that the spread of the basal texture might impart the main reason for the tensile anisotropy in the present AZ61 $\mathrm{Mg}$ alloy as tensile-loaded at room temperature. 
As for the anisotropic superplasticity at $300-400^{\circ} \mathrm{C}$, it is generally accepted that grain boundary sliding accommodated by dislocation slip is the main mechanism for superplastic deformation. The mobility of intragranular dislocations also plays an important role in the mechanism. A reasonable explanation for the anisotropic superplasticity in the present textured AZ61 Mg alloy would be contributed to the mobility of dislocations in the differently oriented specimens. Based on the Schmid factor analysis on the slip systems, it can be realized that the mobility of dislocations in the $45^{\circ}$ sample is the highest. This means that the overlap of grains and the stress concentration due to the grain boundary sliding can be more readily relieved by the movement of high mobility of dislocations, at least in the initial stage of superplastic deformation, because the textural structure is little altered by the small amount of grain boundary sliding and grain rotation at this stage. For this reason, the accommodation with respect to the grain sliding and rotation is expected to occur more smoothly, and grain boundary sliding can continue as the major deformation process. This will lead to lower stress concentrations at the triple points and less occurrences of cavity nucleation, favorable for achieving higher superplastic elongations than the other two $0^{\circ}$ and $90^{\circ}$ samples.

As for the difference in anisotropic superplasticity between the $0^{\circ}$ and $90^{\circ}$ samples, it would be also explained from the uniformity of Schmid factors of the two slip systems, namely, the prismatic $\langle a\rangle$ and pyramidal $\langle c+a\rangle$ slip systems. For the basal slip, there are two sets of the primary basal slip system with the same Schmid factor of 0.15 in the $0^{\circ}$ sample; but only one set with a Schmid factor of 0.17 (with two other sets possessing a very low Schmid factor of 0.08 ) in the $90^{\circ}$ sample (Table 3 ). In the $0^{\circ}$ sample, as one set of dislocations is blocked, another set of dislocations can continue to slip. On the other hand, in the $90^{\circ}$ sample, there is only one set of easy slip system. Once this very easy slip system is blocked, the continuous movement of dislocations becomes difficult owing to the small Schmid factor (0.08) of the other two sets in the basal slip system. Such a condition is similar for the pyramidal $\langle c+a\rangle$ slip systems (Table 3 ). There are two sets of the pyramidal slip in the $0^{\circ}$ specimen possessing a higher Schmid factor, but only one set in the $90^{\circ}$ one. It is suggested that this is the main reason why the $0^{\circ}$ sample consistently exhibits higher superplastic elongations than the $90^{\circ}$ one. Furthermore, the anisotropic superplasticity becomes small at $400^{\circ} \mathrm{C}$ as in Fig. 5. This suggests that the basal slip causes mainly the anisotropy. That is, the difference of critical resolved shear stress between various slip systems becomes smaller at $400^{\circ} \mathrm{C}$. Thus non-basal slip occurs more easily, resulting in the reduction of basal-slip induced anisotropy.

\section{Conclusions}

(1) After warm extrusion, the coarse grains in the cast AZ61 alloy were transformed into refined equiaxed grain structures $\sim 6.5 \mu \mathrm{m}$ in size, implying that strong dynamic recrystallization has fully taken place during extrusion.

(2) The $\{0002\}\langle 10 \overline{1} 0\rangle$ texture is the main component among the sharp basal $\{0002\}$ textures after extrusion, similar to the texture development in rolled $\mathrm{Mg}$. This texture undergoes little changes during subsequent annealing and normal grain growth.

(3) The macroscopic orientation has an important influence on the tensile properties at room and elevated temperatures. The sample oriented at $45^{\circ}$ to the extrusion direction has lower yield strength and higher ductility at $25^{\circ} \mathrm{C}$, and higher superplastic elongations at $300-400^{\circ} \mathrm{C}$, as compared with the $0^{\circ}$ and $90^{\circ}$ samples.

(4) The anisotropic behavior during room temperature tensile loading and the initial stage of superplastic straining are rationalized in terms of the Schmid factor values and the ease of dislocation mobility in various slip systems. The results are in good agreement with the experimental observations.

\section{Acknowledgments}

The authors would like to gratefully acknowledge the sponsorship from National Science Council of ROC under the project NSC 90-2216-E-110-024. The author Y. N. Wang is grateful to the post-doc sponsorship from NSC under the contrasts NSC 90-2816-E-110-0001-6 and 91-2816-E-1100001-6.

\section{REFERENCES}

1) A. Lasraoui and J. J. Jonas: Metall. Trans. 22A (1991) 1545-1558.

2) M. R. Barnett: J. Light Metals 1 (2001) 166-175.

3) M. Mabuchi, Y. Chino, H. Iwasaki, T. Aizawa and K. Higashi: Mater. Trans. 42 (2001) 1182-1190.

4) T. Mukai, M. Yamanoi, H. Watanabe and K. Higashi: Scr. Mater. 45 (2001) 89-94.

5) J. Koike, T. Kobayashi, T. Mukai, H. Watanabe, M. Suzuki, K. Maruyama and K. Higashi: Acta Mater. 51 (2003) 2055-2065.

6) U. F. Kocks, C. N. Tome and H. R. Wenk: Texture and Anisotropy, (Cambridge University Press, Cambridge, UK; 1998) 204-207.

7) Y. N. Wang and J. C. Huang: Mater. Chem. Phy. 81 (2003) 11-26.

8) J. J. Fundenberger, M. J. Philippe, F. Wanger and C. Esling: Acta Mater. 45 (1997) 4041-4055.

9) O. Engler: Metall. Mater. Trans. 30A (1999) 1517-1527.

10) F. J. Humphreys and P. N. Kalu: Textures and Microstructures 14-18 (1990) 703-708.

11) M. Hatherly and W. B. Hutchinson: An Introduction to Textures in Metals, (Chameleon Press, London, UK; 1990) 22-34.

12) F. Wanger, N. Bozzolo, O. Van Landutyt and T. Grosdidier: Acta Mater. 50 (2002) 1245-1259.

13) S. Suwas, R. K. Ray, A. K. Singh and S. Bhargava: Acta Mater. 47 (1999) 4585-4598.

14) H.-J. Bunge: Texture Analysis in Materials Science-Mathematical Methods, (Butterworth \& Co., London, UK; 1982) 20-100.

15) M. H. Yoo, S. R. Agnew, J. R. Morris and K. M. Ho: Mater. Sci. Eng. A319-321 (2001) 87-92.

16) Y. N. Wang, C. J. Lee, C. C. Huang and J. C. Huang: Mater. Sci. Forum 426-432 (2003) 2655-2660.

17) M. T. Perez-Prodo and O. A. Ruano: Scr. Mater. 46 (2002) 149-155.

18) R. E. Reed-Hill and R. Abbaschian: Physical Metallurgy Principles (third edition) (PWS Publishing Company, Boston, USA; 1994) pp. 136-139.

19) M. A. Meyers, O. Vohringer and V. A. Lubarda: Acta Mater. 49 (2001) 4025-4035.

20) J. Koike, T. Kobayashi, T. Mukai, H. Watanabe, M. Suzuki, K. Maruyama and K. Higashi: Acta Mater. 51 (2003) 2055-2065. 